\title{
Fictional Self-Consciousness in Robert Coover's Pricksongs and Descants
}

\author{
Ricardo Miguel Alfonso \\ Universitat Rovira i Virgili
}

\begin{abstract}
This essay reads Robert Coover's novel Pricksongs and Descants as an instance of the interchange between mimetic representation and literary self-reflexivity characteristic of postmodern novelists such as Vladimir Nabokov or John Barth. It analyses some of the short stories collected in this volume as examples of Coover's ongoing concern with the interchange between (1) our perception of the real, (2) the systems of thought by means of which we account for the flux of reality, and (3) the epistemological nature and function of literature as a vehicle for modern self-understanding. The result is not only a (literary) experiment in which the structures of the traditional, linear novel are relentlessly questioned, but also an inquiry into the possibility of tracing a clear-cut distinction between fiction and reality and, subsequently, between art and life.
\end{abstract}

Besides dealing with mimetic forms of various kinds in earlier fictions, notably in The Origin of the Brunists (1966) and The Universal Baseball Association (1968), Robert Coover has also explored the implications of mimetic representation in the specific context of literary texts. The short stories collected in Pricksongs and Descants (1969), most of them written and published in American journals and magazines before the appearance of his first novel, explicitly examine fundamental aesthetic categories by throwing them into question. Pricksongs and Descants is in fact a collection of experimental short stories whose concern is the very limits of literary representation. The role of the author, the narrative line, the boundary between reality and fantasy, and other concepts and paradigms are examined in a set of short fictions that deals with the question of meaning- and fictionmaking in the universe of literary production. In his third published book, then, Coover plunges into the field of storytelling and thereby narrows the exploratory breadth of his earlier works. And although in fact some of the issues he delves into could be metaphorically expanded in order to embrace other non-fictional representational processes, here I prefer to limit my analysis to the strictly literary concerns of the anthology. 
The scope of Coover's collection is, however, larger than the examination of the categories of the literary text. The stories collected in Pricksongs and Descants seem to thematize not only an interest in issues of literary practice. In a frequently-quoted passage taken from the "Prólogo y dedicatoria a don Miguel de Cervantes Saavedra," the introduction to the "Seven Exemplary Fictions," Coover clearly explains what his collection is meant to reflect. The general aim of this anthology, as put forward in this summary of his concerns, is not only to delve into the narrowly textual level of literary narrative. As in other works, Coover is especially interested in disclosing the parallel relationship between the literary practice and the broadly sociocultural scene of a given era-that is, how certain forms of writing fiction embody the cultural changes of a period. In Pricksongs and Descants, this relation is examined through the medium of fiction itself-largely in terms of the crisis of the traditional notions of mimetic representation and realism. The sense of exhaustion so characteristic of post-World War II society is clearly reproduced, in Coover's view, in literature-especially as reflected in such features as fragmentation and self-consciousness or the attacks on realism and linearity. To begin with, in the following passage from the "Dedicatoria," Coover implicitly sees Barth's notion of the "literature of exhaustion" as a reflection of the crisis of contemporary culture and a sign of a radical change in our conceptions of reality and nature:

[T]he optimism, the innocence, the aura of possibility you [Miguel de Cervantes] experienced have been largely drained away, and the universe is closing in on us again. Like you, we, too, seem to be standing at the end of one age and on the threshold of another. We, too, have been brought into a blind alley by the critics and analysts; we, too, suffer from a "literature of exhaustion," though ironically our nonheros are no longer tireless and tiresome Amadises, but hopelessly defeated and bed-ridden Quixotes. (78)

While the characterization of contemporary fiction as an appropriate indicator of the crisis of post-industrial societies has become a widely agreed-upon conception, the question whether this crisis has led us-or seems to be leading us-to a new conception of man, society and the sciences at large is more than disputable. The partial success of the postmodern novel as a "sign of the times," is understood by many critics exclusively in terms of formal innovation, in the sense that the novel is taken to represent (in itself, in its own theme and structures) not only the impasse of mimesis and extraliterary reference in literature but also, broadly speaking, the collapse of the whole philosophical and humanistic tradition. However radical, the possibility any such change in our received cultural paradigms turns out to be a purely formal reconfiguration of what we already know.

These are, basically, the similarities in the motives for fiction in Cervantes's and Coover's eras-despite the obvious differences between other aspects of their fictionmaking techniques. The radical transformation of worldviews is the tacit theme of this anthology of short fictions - the most explicit concern being, of course, the exploration of the form of the genre itself. Cervantes's work in many senses reflects the transition from the Middle Ages to the Renaissance and, in the literary field, from romance to the novel, whereas for many critics Coover's represents the replacement of the modernist dream of 
universal history by the postmodern "imperative" of eventuality and anti-essentialism. The object of Pricksongs and Descants is, in the light of the implicit argument of this passage, an examination of how changes in cultural patterns are reflected in the cultivation of certain contemporary fictional forms. "We seem to have moved," Coover continues,

from an open-ended, anthropocentric, humanistic, naturalistic, even-to the extent that man may be thought of as making his own universe-optimistic starting point, to one that is closed, cosmic, eternal, supernatural (in its soberest sense), and pessimistic. The return to Being has returned us to Design, to microcosmic images of the macrocosm, to the creation of Beauty within the confines of cosmic and human necessity, to the use of the fabulous to probe beyond the phenomenological, beyond appearances, beyond randomly perceived events, beyond mere history. (78)

The change in the ways of knowledge that Cervantes and Coover seem to share is made clear in this passage. Contemporary fiction rejects traditional humanism and subscribes to the exploration of how we confront the randomness of phenomenological reality. In so doing, the novel refuses to accept its conventional fundamentals beforehand by choosing, in turn, to examine how these fundamentals work. What Coover here identifies as "the return to Being"-an expression with Heideggerian resonances, also used by Robbe-Grillet in For a New Novel-is the postmodern fictionist's tendency to explore, and call into question, the essence and organization of things provided by culture and society through what is frequently referred to as "humanistic knowledge."

There is also in this passage a suggestion of the mimetic character of contemporary literature. By focusing on the "microcosmic image of the macrocosm," the novel gives up the representation of universal truths and examines the particularity and contingency of our views of reality. Postmodern fiction thematizes the inadequacies between the allcomprehending import of universal truth-claims, on the one hand, and the uniqueness of specific cultural situations, on the other-which is, in my view, what Coover seems to convey in this passage. The result is a variety of fiction that inevitably casts doubt on almost every kind of truth-claims, whether aesthetic, historical or philosophical. In the context of fictional representation, and this is probably more prominent in Pricksongs and Descants than in other works by Coover, this contrast is embodied by the sort of critical interchange between the creative and representative facets of mimesis, whereby the essentials of mimetic representation-straight referentiality, authorial detachment, characters unaware of their fictional status-are ceaselessly unsettled.

The stories collected in Pricksongs and Descants definitely ratify the return to Design (in the sense of formal exploration) brought about by postmodern narrative fiction-as reflected, for instance, in the works of Federman, Barth, Sukenick or Nabokov. Coover's short fictions engage the various possibilities of anti-realism and non-linear narration, as well as the interplay between reality and imagination. The subject of the collection is, in this sense, the relation, conceived of in terms of dissimilarity, between the devices displayed by the stories themselves and other traditional, already-established fictional codes (Durand 134). These devices-such as texts with no punctuation, narratives canceled by the author's commentaries, and so on-are so removed from the conventionally accepted 
forms of the genre, from 19th-century realism to the modernist novel, that they not only call into question the text's referential quality or play with different possible structures, but also dismantle the reading experience itself. By offering not only alternative perspectives but also mutually contradictory accounts of the same events, Coover undermines any expectation of closure. In this sense, Pricksongs and Descants, probably better than any other of Coover's novels, constitutes a brilliant example of the crisis that realism has undergone with the advent of postmodern fiction (see Kuehl and Nash).

In exploring the possibilities of realism and literary creation, some of these short fictions also become, as many critics put it, "self-conscious of their status." One of the purposes of Coover's Pricksongs and Descants is the dismantling of the basic conventions of linear narrative and fictional coherence. Each fiction thematizes, and criticizes, one or several organizing principles of the realist novel-from authorial non-intervention to profound psychological characterization (see Schmitz). The beginning of "The Magic Poker," one of the most celebrated of the stories included in the collection, illustrates this tendency:

I wander the island, inventing it. I make a sun for it, and trees-pines and birch and dogwood and firs - and cause the water to lap the pebbles of its abandoned shores. This, and more: I deposit shadows and dampness, spin webs, and scatter ruins. Yes: ruins. A mansion and guest cabins and boat houses and docks. Terraces, too, and bath houses and even an observation tower. All gutted and window-busted and autographed and shat upon. I impose a hot midday silence, a profound and heavy stillness. But anything can happen. (20)

Few passages in the entire field of contemporary fiction exemplify so brilliantly the self-conscious thrust of the novel in recent decades. The self-referential direction (or inward turn) of the story is here relentlessly disclosed. In other words, creative mimesis (mimesis ${ }_{3}$ ) lays bare the very working of representative mimesis (mimesis ${ }_{2}$ ) by making both activities appear the same: as we give names to things in order to apprehend the world, so Coover brings objects into (fictional) existence by naming them. But the passage not only effectively flaunts the fictional character of the narrative but also, as we will see, presents the narrator-creator not as the master of his creation but as just another formal component, as liable to variations and hesitations as are the plot or the characters. ${ }^{1}$ With these introductory remarks, Coover makes it clear from the beginning of "The Magic Poker" that the creator's self-conscious grasp of his very creation falters at various points. The influence of this strategy on the text's configuration and narrative coherence is obvious. The reader's expectations of closure, consistency or progress in the plot are invariably disrupted-strictly, there seems to be no plot at all. Sometimes, for instance, the author is dissatisfied with the development of the story. Then, he stops and changes the course of the narrative:

Wait a minute, this is getting out of hand! What happened to that poker, I was doing much better with the poker, I had something going there, archetypal and even maybe 
beautiful, a blend of eros and wisdom, sex and sensibility, music and myth ... Back to the poker. (\#29)

At times, he also distrusts his own command over the characters. Unlike the players of Henry's Universal Baseball Association, who basically remain under their author's control throughout the novel, the characters of this story seem to enjoy a life of their own. They seem to appear and disappear at will. Sometimes the narrator loses sight, as it were, of some of his characters. Reversing the relation of authority between the creator and his/her creation, he even wonders who actually invented whom:

But where is the caretaker's son? I don't know ... Didn't I invent him myself, along
with the girls and the man in the turtleneck shirt? Didn't I round his back and stunt his
legs and cause the hair to hang between his buttocks? I don't know. The girls, yes, and
the tall man in the shirt-to be sure, he's one of the first of my inventions. But the
caretaker's son? To tell the truth, I sometimes wonder if it was not him who invented me.
(\#22)

In many ways, "The Magic Poker" casts doubt on almost any possible notion of fictional representation-to such an extent that its all-pervasive authorial self-awareness and ceaseless flaunting of its composition contribute to articulate Coover's most overtly selfreferential fiction. Certainly, it stands out among his works as the one which most drastically carries self-consciousness to the extreme. But "The Magic Poker" not only exposes its own compositional artifices. Among the various self-conscious devices it displays, it thematizes the figure of the narrator as another textual artifice (in \#1, \#3, \#7, $\# 11$, \#22, and many more), it plays with analepsis and prolepsis only to revoke the narrative it has previously articulated (\#8), and finally transforms the story into a legend focusing on multiple elements and characters (the poker in \#48, the caretaker in \#49, the two girls in \#50, and Karen's gold pants in \#52). These devices crucially contribute to the radical indeterminacy of the story, in which the pervasive self-reference makes it impossible for the reader to find any stable structure of meaning or narrative coherence (Stengel 103).

By enhancing and exposing its own artificiality, the fictions collected in Pricksongs and Descants-notably "The Magic Poker," the "Seven Exemplary Fictions" and "The Babysitter"-constitute a challenge even to the most comprehensive theories of mimesis. ${ }^{2}$ As the standards of representation are exclusively limited to self-representation, so the text's relation to the extraliterary world diminishes. The mimetic aspect of "The Magic Poker" is to be taken in terms of the "artistic impulse" of aesthetic world-making that Coover's novels often explore. Unlike in The Universal Baseball Association, in which we can study narrative changes without necessarily resorting to the figure of Henry Waugh, Coover makes it very difficult to approach "The Magic Poker" without taking the narratorcreator into consideration. It is in fact his voice that self-consciously dismantles his own construction, changes the narrative perspective at will, and forces the reader to choose between more than one possible explanation of the same (random) sequence of occurrences. In this sense, Coover's exploratory excursion into mimesis in "The Magic 
Poker" must be regarded as an inquiry into the limits of the relationship between literary representation and the author's control over this representation. In this short story, this relationship is undermined, as the original total mastery ultimately leads the narrator himself to distrust of the power to intervene in his own text.

The absence of mediation by a fictional narrator between the reader and the characters in "The Magic Poker" not only reinforces the self-referential direction of the story's narrative line, which makes it fold up on itself at numerous points. It also contributes to the recurring obliteration of mimesis and realism $I$ have already pointed out. ${ }^{3}$ The story's most self-conscious moments are in fact provided by the narrator's direct observations and suggestions to the reader, who, in turn, cannot but surrender to Coover's playful designs. In this short fiction, ironically, Coover plays the same god-author role that Henry Waugh played in the Universal Basketball Association, the only difference between the two being the textual and structural function of their respective authorial commentaries. Henry leads us through the construction and growth of a fictional system which is already within another fictional system (the mise-en-abyme effect is clear here) whereas Coover's selfreferential comments not only expose the story's artificiality but in fact articulate the story itself. As narrator, Coover introduces us, via Henry Waugh, into the Universal Basketball Association as a second-order fictional world, while in "The Magic Poker" he directly introduces us into a first-order one. It is in this sense that many of the stories collected in Pricksongs and Descants - not only "The Magic Poker"-constitute an outstanding variation in Coover's reflexive works, not so much in the scope of his explorations but rather in the degree of reflexiveness and textuality to which he carries them.

Coover's exploration of literary representation, of which the question of the narrative voice is an element, is nevertheless carried out in ways different from those he employed in other works. What in previous fictions were basically thematical and formal explorations-in The Origin of the Brunists and The Universal Basketball Association, respectively-now emerge as structural (also grammatical) inquiry into fictional forms. Coover's strategies in his 1969 collection momentarily give up the critical thematization of a fictional system clearly detached, as a mimetic construction to be explored, from his novel's own constitution as such. Until Pricksongs and Descants, as well as in his later works, Coover keeps his thematic concerns aside from the novels' own structures and the representational designs employed, allegorical readings and would-be mise-en-abyme effects being more critical contrivances than actual characteristics of his novels.

The mimetic features of Pricksongs and Descants are rather infrequent, although some of Coover's concerns in other fictions can be found. His overtly self-conscious references to the problems of representation in "The Magic Poker" do not for the most part point at the problems in the relation between words and things, an interest shared by American metafictionists. ${ }^{4}$ Rather, it probes into the problems that arise when a mimetic structure-fictional-literary, in this case-is articulated by its author and is taken to represent a set of characters and events. (In The Origin of the Brunists and The Universal Basketball Association we see how mimetic constructions tend to grow self-conscious and thereby do without their creators. Here we seem to be aware of their inner self-canceling thrust. $)^{5}$ 
As in other Coover's novels, notably The Origin of the Brunists, here mimesis again appears as a struggle against chaos. The unnamed tall man who intermittently shows up in the story in many senses voices the view of mimesis Coover will set forward in the Universal Basketball Association:

The tall man stands, one foot up on the stone parapet, gazing out on the blue sunlit lake, drawing meditatively on his pipe. He has been deeply moved by the desolation of this island. And yet, it is only the desolation of artifact, is it not, the ruin of man's civilized arrogance, nature reclaiming her own. Even the willful mutilations: a kind of instinctive response to the futile artifices of imposed order, after all. But such reasoning does not appease him. Leaning against his raised knee, staring out upon the vast wilderness, hoping indeed he has heard a boat come here, he puffs vigorously on his pipe and affirms reason, man, order. Are we merely blind brutes loosed in a system of mindless energy, impotent, misdirected, and insolent? "No," he says aloud, "we are not." (\#25)

Again Coover's interest is the confrontation between phenomenological randomness and human order. The desolation of the island the narrator has invented appears as the result of the fiction-making process that generates it. It is, paradoxically, the same process of formation that ultimately dries up, as it were, the reality at which it (mimetically) points. The development of a fictional structure entails, in his view, the inevitable destruction of the immediacy of the reality that surrounds it. Basically, as in so many of his novels, the purpose of this destruction is the imposition of the categories of abstract thinking -symbolized by the working of "order" and "reason"-on our understanding of reality, a meaning-making process turning us from brutes into human beings.

A significant effect of this loss of immediacy is the narrator's anxiety that what began as an imaginative construction may end up as a substantial, tangible truth. (This clearly anticipates a central theme of Coover's entire career as a novelist.) Whether or not it is he who has created the characters (\#26) increasingly becomes a radical questioning of the narrator's authority over the whole text:

At times I forget that this arrangement is my own invention. I begin to think of the island as somehow real, its object solid and intractable, its condition of ruin not so much an aesthetic design as an historical denouement. I find myself peering into blue teakettles, batting at spiderwebs, and contemplating a greenish-gray growth on the side of a stone parapet. I wonder if others might wander here without my knowing it; I wonder if I might die and the teakettle remain. "I have brought two sisters to this invented island," I say. This is no extravagance. It is indeed I who burdens them with curiosity and history, appetite and rhetoric. If they have names and griefs, I have provided them. (\#37)

The intractability of things seems to be the outcome of their use as signifieds instead of signifiers in literary representation. In ascribing meaning to beings and events-by representing them, whether referentially or metaphorically - we are trying, Coover implies, to impose a structure on referents. In so doing, the words ultimately replace the objects themselves. It is this process, also found in the rhetoric of ideological structures, that many contemporary metafictionists want to unveil. In this case, Coover discloses this complicity 
by having his narrator reflect on the possibility that the text not only outlives its own author but even that some other characters he has not invented-and who, therefore, have nothing to do with it-can also wander the island. In so doing, the opposition between fiction and reality disintegrates, the idea of the author detached from his creation collapses as his own sense of reality vanishes (Siegle 206).

Toward the end of "The Magic Poker," the materialization of the text seems to come true, and Coover's construction is becoming alive. Like the characters in the Universal Basketball Association, the created figures can eventually free themselves from their author's command. But this freedom does not last long. After having disappeared momentarily to let the narrative flow by itself, he returns to remind us readers that the text is still in his grasp. Despite the irregularity of the narrative line, which in traditional terms might suggest a total loss of authorial control, the figure of the narrator reappears, not only to demonstrate his power and control over the text, but also to claim that everything we take to be real is a figment of the imagination:

I am disappearing. You have no doubt noticed. Yes, and by some no doubt calculable formula of event and pagination. But before we drift apart to a distance beyond the reach of confessions (though I warn you: like Zeno's turtle, I am with you always), listen: it's just as I feared, my invented island is really taking its place in world geography ... I look on a map: yes, there's Rainy Lake, there's Jackfish Island. Who invented this map? Well, I must have, surely ... Yes, and perhaps tomorrow I will invent Chicago and Jesus Christ and the history of the moon. Just as I have invented you, dear reader, while lying here in the afternoon sun, bedded deeply in the bluegreen grass like an iron poker. (\#46)

The parallels between all these passages and some of the reflexive concerns I have studied in the Universal Basketball Association story are striking. The process of materialization of an aesthetic construction that the narrator explains here in many senses anticipates the Universal Basketball Association reflexive explorations (the fictions collected in Pricksongs and Descants were written before the publication of Coover's first novel). The position and narrative role of Henry Waugh and the narrator of "The Magic Poker" are almost the same. The process of "becoming alive" that the island increasingly undergoes in fact bears a strong resemblance to the development of Henry Waugh's Universal Basketball Association in his 1968 novel. In probing into mimesis, both "The Magic Poker" and the Universal Basketball Association-and also, though to a lesser extent, The Origin of the Brunists and The Public Burning-engage the problems of the referential transparency and, more importantly, epistemological validity of fictional representation that have become the widely discussed topics of literary theory and criticism in recent decades. In so doing, they can be well regarded as typically postmodern-although, for Coover, not anti-realist-works of fiction that share some of the central concerns of contemporary American literature.

The relevance of myth in Coover's short stories also greatly differs from that of his other novels. In "The Magic Poker," the legend that the story of the magic poker becomes (especially from \#48 onwards) constitutes just one more possible explanation of the story told, as valid and ultimately self-canceling as any other. In Pricksongs and Descants, 
textual representation lacks the substantial meaning and "epistemological reliance" of other fictional-mythical constructions, such as the Brunist meeting at the Mount of Redemption, the Rosenbergs' execution, or the recreation of the Great Confrontation at the Universal Basketball Association stadium. The fictionalized worlds do not finally materialize for the reader to recognize, and reconstruct, them in mimetic-hermeneutic terms. ${ }^{6}$ So it is that the reader is ultimately left with the experience of having read a text that is a complex net of events and characters, often mutually exclusive, which does not lead him/her anywhere but to mere contemplation. (To what extend this constitutes a valuable exercise would require extended discussion.)

Among the fictions collected in Pricksongs and Descants, "The Babysitter" is a good instance of this unsettling tendency. ${ }^{7}$ This short story merges reality and dream in such a way that it is impossible to discern one from the other. The story is as follows: an unnamed babysitter comes to watch Dolly and Harry Tucker's three children while they go to a party. The babysitter's boyfriend Jack and his friend Mark are trying to take advantage of her, so they decide to go and pay her a visit. While Harry Tucker gets drunk at the party and fantasizes about seducing the babysitter, Jack and Mark also imagine themselves raping her, spanking her, or even spying on her in the bath (\#48, \#58, \#76). Here the set of plot-variations is similar to that of "The Magic Poker": Mr. Tucker returns home and catches the babysitter half undressed, throws Jack out and takes advantage of her (\#59); or he catches her in the tub and joins her (61); or she is just watching TV peacefully (\#71); or Jack and Mark catch her in the tub and accidentally drown her (\#97). (These are just a few possibilities Coover provides the reader with.) In the last scenes, we see a report on the TV that a babysitter has been killed. There are, however, two contradictory versions: (1) that the victim has been another babysitter, so that the evening ends normally at the Tuckers' house, on the one hand, and (2) that everything is true, the children have been murdered, the husband disappears leaving her corpse in the bathtub, on the other. (For a complete list, see Kennedy 63-64.) All these possible denouements take place in the same text, but none of them prevails over the others. Equally valid as they are, none can be thought of as the true account of the story of the babysitter. As in "The Magic Poker," the fictional world of this story contains antithetical endings, none of which seems reliable at all. The closure we may expect from a short story is frustrated. The changing TV reports, which is what the reader is left with at the end of the story, do not resolve the interpretive problems the text poses throughout.

The "innovative" devices Coover displays in "The Babysitter" are various, all of them conveying, again, an exploration into mimetic representation. Among them, we have the text's unique anti-structure, the sectioned-off narrative line, and the psychological abnormality of its characters (see Weinstock). The latter feature, but not the former, is here more prominent than in "The Magic Poker." The blocking off of the scenes precludes the smooth narrative transition. The temporal reconstruction of the plot becomes increasingly problematic due to the endless analepses and prolepses Coover employs-although the common links between the different paragraphs help the reader to reconstruct the story in its full complexity. The disparity of points of view also contributes to disrupt the reader's expectations of causality and continuity by constantly changing the reader's perception of 
the story-although, until the multiple-choice end, this does not ultimately cancel out his/her reconstruction of the narrative.

Even though the mimetic-hermeneutic actualization is not completely destroyed in any of these short fictions, the logic of mimetic representation is indeed radically questioned. Coover's intention is not, however, to start the institution of literature anew, but rather to read the background of tradition (myths, genres, codes) through postmodern experimental forms-pop-culture, cinematic techniques, etc. (Wilczynski 514). This is another parallel in the art of fiction between Cervantes's and Coover's eras. As he puts it in the "Dedicatoria,"

[Y]our stories [Cervantes's] also exemplified the dual nature of all good narrative art: they struggled against the unconscious mythic residue in human life and sought to synthesize the unsynthesizable, sallied forth against adolescent thought-modes and exhausted art forms, and returned home with new complexities. In fact, your creation of a synthesis between poetic analogy and literal history (not to mention reality and illusion, sanity and madness, the erotic and the ludicrous, the visionary and the scatological) gave birth to the Novel-perhaps above all else your works were exemplars of a revolution in narrative fiction, a revolution which governs us - not unlike the way you found yourself abused by the conventions of Romance-to this very day. ( $P \& D 77)$

The first step in this adaptation of the tradition is, he thinks, to disrupt the basic reading expectations of the novel genre-linearity, chronological consistency, etc. To this purpose, " $[t]$ he reader is continually made aware that the pattern set before him is arbitrary and can be broken, that other perspectives are possible, and that the reader and Coover are engaged in a game of choices" (McCaffery, Metafictional 61). (The notion of the literary text as a game, a recurrent idea in contemporary fiction and theory, is an appropriate metaphor for experimental fiction-making, as demonstrated by Coover's or Barth's short stories.) The imaginative and perceptive faculties of the implied author and the implied reader often overlap to the extent of becoming almost indistinguishable that is why both Coover and his readers enjoy the same narrative status when we see his various imaginary constructions enjoy a life of their own. With this strategy, Coover tends to identify himself with the reader-whom he has, at least in "The Magic Poker," invented for the purposes of the story-and therefore consciously blurs the boundaries between his creative experience and the reader's reconstructive task. (This playful transformation and enlargement of the reader's response to the fictional work is much more powerful in many of the stories collected in Pricksongs and Descants than in Coover's later works, in which the detachment of the reader is, despite open endings, consistently preserved.) In so doing, he levels out the activities of both, suggesting a notion of literary interpretation as an interactive exercise.

Finally, "Morris in Chains," another of the short fictions collected in Pricksongs and Descants, also thematizes Coover's interest in pattern and order, this time in the form of a conflict between the influence of science and technology on the designs of nature. Much more accessible than others in this anthology, this story deals with the topic of the simple countryman-shepherd Morris, in this case dehumanized by the powers of modern 
machinery. In this story, Morris, unaware of his importance as a remnant of the innocence and purity in which human beings lived before the advent of technological progress, is chased by a group of all-seeing and omnipotent scientists led by Dr. Doris Peloris-who controls the weather and the course of rivers, among other things, from their Expedition Headquarters. "Morris in Chains" also thematizes the reduction of unexplained, or misunderstood, phenomena to the patterns of formulation and knowledge of the scientific community, and so the story can be regarded as a parody of the scientists' pattern-making imagination, whose aim is to adapt whatever remains unknown to our understanding. The overriding importance attached to this activity (inevitably reductive, as Coover sees it) is revealed by the crisis within the scientific perfectly ordered world brought about the failure of earlier attempts to apprehend Morris:

[P]erhaps due to an underestimation of the adversary's perverse vitality, those early expeditions were all too often subverted by disorder, what we can now see as undeniable disorder, were little more than a random series of spontaneous incursions of the sort that most suited Morris' own patternless and irresponsible life. (48)

The failure of these expeditions is now seen, as this passage makes clear, in terms of the precariousness of their preparation, that is, their inability to cope with the randomness of the world's phenomena. It is obvious that their predecessors could not chase Morris because they did not have the ability to schematize, and thus predict, every aspect of Morris's life. Like a 20th-century car-driver watching a 19th-century carriage, Dr. Peloris's group can only see their predecessors' attempts in the light of their lack of technological advancement.

However, when the story begins Dr. Peloris and her set of well-equipped colleagues have already managed to locate the shepherd because of his patterned life. After an easy, patterned reasoning, they have achieved what the others could not. They have been able to adjust Morris's unreflecting movements to their own predictions-which is, metaphorically, a "sign of the times," a proof of the "blind alley" to which, according to Coover's "Dedicatoria," we have been led by critics and analysts (78). Gathered to arrange Morris's capture, Dr. Peloris acquaints the group with the process they will follow in order to capture the shepherd:

Our strategy is divided into two parts ... the pursuit and the trap. The second of course depends on the first, which is essentially a fact-finding mission, but which at the same time may serve the complementary function of harassing and exhausting the adversary, forcing predictable pattern-reliance: the wearier, the unwearier. (50, my emphasis)

The pursuit of Morris appears as another pattern-making activity, a "fact-finding" task, by virtue of which the scientists have to make Morris rely on certain patterned behavior. The result of the overall process is, besides their overwhelming control of nature, the scientists' omniscient knowledge of Morris's life, yet always within their own patterns, of course: 
"You see, Nan ... it is now certain that Morris will camp here in this valley, beside this canal and that grove, within five days. The order of his disorder . . forces him to do so no matter what operations his mind might undertake in order to arrive at what he would tend to think of as a decision. Unless, of course, it included the foreknowledge that we await him here. And who knows? perhaps even this knowledge would not suffice to break the power of pattern over mere mind-activity." (55)

This amazing ability to foresee the movements of Morris is simply the scientists' reduction of disorder to order. Unable to transcend their own patterned methodology, they diminish Morris's life to a sort of entropy, the "order of disorder" that serves their research and ideology. By mediating between the scientists' view and the reader's, Coover rehearses the basic structure of The Universal Basketball Association, inasmuch as he does not intervene in the text to undermine its most basic representational processes.

Written before the publication of his most celebrated novels, the short fictions anthologized in Pricksongs and Descants anticipate some of their author's reflexive interests. The difference between these short stories and Coover's other works studied here is, as I have pointed out, the degree of textualization enjoyed by the narrative devices through which he examines mimetic representation. The identification between authornarrator and reader, many undecidable endings, and the authorial commentaries which substantially alter the course of the narrative are but a few tricks Coover uses to defamiliarize readers in their interpretive task and carry us away from the conventions of the mimetic-realist novel. In so doing, Coover aligns himself with a group of contemporary authors-Beckett, Nabokov, Barth, Hawkes, Gass, Sukenick-whose central interest is the dismantling of the assumptions of the novel genre, notably as it was formulated and accepted throughout the 19th century. In a review of Pricksongs and Descants, William H. Gass identifies Coover's play with scenes in his short fiction as a card-game, and summarizes the reflexive concerns of the collection as follows:

[T] he experimental methods which interest Coover, and which he chooses to exploit so skillfully, are those which have to do with the orderly, objective depiction of scenes and events, those which imply a world with a single public point of view, solid and enduring things, long strings of unambiguous action joined by tight knots, even when the material itself is improbable and fantastic; and the consequence of his play with these techniques is the scrambling of everything, the dissolution of that simple legendary world we'd like to live in, in order that new values may be voiced; and, as Coover intends them, these stories become "exemplary adventures of the Poetic Imagination." (Gass 108)

This passage is relevant because it brings together two different sides of a substantial part of Coover's fiction. Although it does not distinguish the narrative from the critical explorations of his work, it summarizes some of the featuress I have discussed so far.

In the first place, Gass points at the antirealist devices displayed throughout Pricksongs and Descants " "those which have to do with the ordered, objective depiction of scenes and events"-which also appears in other works, and can be seen as a prominent feature of reflexivity in Coover's narrative. From the unrealistic experiences of Henry Waugh and Richard Nixon to the unreliable narrators and characters of his 1969 collection, the reading 
conventions of the novel genre in the 19th century and the psychological profundity of modernist fiction are explored, and sometimes mocked. His fiction approaches what can be called a "fictionalized version of literary criticism." To put it another way, using Scholes's formulation, Coover's self-conscious fiction "assimilates all the perspectives of criticism in the fictional process itself" (Scholes 106). This focus on the purely narrative strategies corresponds to the view of a novelist who, like Gass, has been writing metafiction since the early 1960s. According to him, the central interest of Coover's Pricksongs and Descants lies in the anticonventional approach to narrative it proposes. However, and this is rather unusual in Coover critics and reviewers, this is not the only reason why this collection appears interesting. For Gass, and I agree with him, there is something else beyond the fireworks of textual artifice and myth-play.

Although much more disputable, however, the second important point in this passage is Gass's notion of Pricksongs and Descants as an attempt to "scramble everything" in the world, whether literary or real-life. Typical of postmodern formalism, this conception features the textual-deconstructive side of Coover's work, neglects the relation between his fictions and the surrounding cultural situation, and thus does little justice either to its narrative exploration or to its overt critical aims. Though his view is also that of a metafictionist, more concerned with literary artifice than with mimetic and referential matters, Gass nevertheless recognizes the existence of new values in Coover's criticism of mimesis, causality and narrative-something that, in my view, many Coover critics miss in their assessments of his works. Although he does not delve into what the nature or function of these values can be, at least he seems to perceive them. Given the brevity of Gass's overview-the passage is cited from a review of the collection-I will finish with what the grounds for distinguishing these values can be.

In a career like Coover's, whose narrative works may be characterized not only by their critique of mimetic representation but by other equally broad concerns, the use of openly self-conscious strategies is often regarded as the dominant feature of his oeuvre. Many critics, in fact, have reduced the more or less covert representational interests to the formal disposition of the thematized materials. In so doing, they inevitably tend to disregard what is, in my opinion, the core of Coover's narrative work as a whole. The use of self-referential devices helps to enhance reflexivity-which must be already present in the text-and often also contributes to make the critical interests more visible or understandable, as it were. But these are formal and compositional choices the author makes, all of which largely constitute what is frequently referred to as "style." The new values at which Gass points in his review of Pricksongs and Descants are, especially for the non-formalist critic, significantly separate from literary experiments of the kind cultivated by so many postmodern novelists throughout the 1960 s and 1970 s. In the context of Coover's fiction, this separation between formal playfulness and reflexive concerns is more easily discernible than in the narrowly textual compositions of other contemporary authors-Markson, Acker, Federman, Sukenick-for whom the latter facet does not seem to exist at all. This suggests that we can conceive of Coover's narrative as an example of postmodern fictional experiment, but not without taking into account that (1) his works almost invariably invite a reflection on the powers and limits of representation, whether or not strictly literary, and (2) that his overtly self-referential 
fictions are in fact the most radical stage of reflexiveness. In other words, there is, as I see it, no way to approach Coover's metafictional and self-conscious fictions without considering how these are one step further in the more general phenomenon of fictional reflexivity. These two features make up the "new" value of Coover's narrative. (Obviously, this is not an entirely new merit, although it is sometimes difficult to find in contemporary fiction.) The refusal to acknowledge how both metafiction and selfconsciousness constitute a thematic concentration-and, eventually, a formal and structural radicalization - of mimesis will inevitably neglect the representational qualities that, despite efforts to demonstrate otherwise, the postmodern novel deploys.

\section{Notes}

1. "The Magic Poker" is a collage of fifty-five unnumbered, juxtaposed fragments. In order to simplify my analysis, passages will be identified and numbered in the order Coover arranges them, and quoted preceded by \#.

2. The challenge this text poses is to be understood, in my view, in terms of its anti-realist devices and its flaunting of mimetic representation. Its examination of fiction-making and, in general, writing is, as in other novels by Coover, fundamentally formal and structural-neither ontological nor epistemological. For an analysis opposite to mine, see Siegle, for whom Coover's story uncovers "the pretense of mimetic fiction to bridge this gap [between language and reality], to make the fictional world essentially equivalent to that of reality-at-large" (203). In taking for granted that mimesis attempts to level out the cognitive force of words and things, this textualist approach fails to acknowledge the exploratory import of contemporary fiction in terms of the interchange between the representative and the broadly creative sides of mimesis.

3. I assume that it is Coover himself who is, through the first person used by fictional narrator's voice, directly addressing the reader in his abundant self-conscious remarks. I intentionally do so because no hint of any mediating figure between Coover and us is given throughout this story. There is absolutely no trace of a surrogate fictional narrator clearly distinct from the author-such as, for instance, Sterne's Tristam Shandy. For an argument parallel to my own, see Andersen 97ff; for the opposite view, see Kennedy 18-19. On the other hand, the idea of a narrative line in "The Magic Poker," as well as in so much contemporary fiction, certainly poses certain problems; however, by this term I intend to designate the progress or development of the narrated events.

4. Coover withdraws himself from metafictional writers in the following terms: "I know there's a way of looking at fiction as being made up of words and that therefore what you do with words becomes the central concern, but I'm much more interested in the way that fiction, for all its weaknesses, reflects something else-gesture, connections, paradox, story" (McCaffery, "Robert Coover" 52).

5. With this parenthetical commentary, I do not intend to trace a sort of "evolution" within Coover's work, an idea he has insistently denied. Rather, I try to delimitate two sides of mimetic representation that Coover explores in his fiction, both of which always appear intermingled.

6. For the concept of mimetic-hermeneutic actualization, I rely on Paul Ricoeur's formulation of mimesis ${ }_{3}$, in the first volume of his Time and Narrative. Here actualization is "the final indicator of the refiguring of the world of action under the sign of the plot" (77). For Ricoeur, even 
so-called antinovels "satisfy both the tradition they leave behind and the disorganized experiences they finally end up imitating by dint of not imitating the received paradigms" (73).

7. For my brief discussion of "The Babysitter," I will also use the sign \# to refer to the 107 unnumbered passages in the order in which Coover presents them.

\section{Works Cited}

Andersen, Richard. Robert Coover. Boston: Hall, 1981.

Coover, Robert. Pricksongs and Descants. New York: Dutton, 1969.

Durand, Régis. “The Exemplary Fictions of Robert Coover." Les Américanistes: New French

Criticism on Modern American Fiction. Ed. Ira Johnson and Christiane Johnson. Port

Washington: Kennikat Press, 1978. 130-37.

Gass, William H. Fiction and the Figures of Life. New York: Knopf, 1970.

Kennedy, Thomas E. Robert Coover: A Study of the Short Fiction. New York: Twayne, 1992.

Kuehl, John. Alternate Worlds: A Study of Postmodern Antirealistic American Fiction. New York:

New York UP, 1989.

McCaffery, Larry. The Metafictional Muse: The Works of Robert Coover, Donald Barthelme, and William H. Gass. Pittsburgh: U of Pittsburgh P, 1982.

. "Robert Coover on His Own and Other Fictions: An Interview." Novel vs. Fiction: The

Contemporary Reformation. Ed. Jackson I. Cope and Geoffrey Green. Norman: Pilgrim Books, 1981. 45-63.

Nash, Christopher. World-Games: The Tradition of Antirealist Revolt. London: Methuen, 1987.

Ricoeur, Paul. Time and Narrative. Vol. 1. Trans. Kathleen Blamey and David Pellauer. Chicago:

U of Chicago P, 1984.

Schmitz, Neil. "Robert Coover and the Hazards of Metafiction." Novel 7 (1974): 210-19.

Scholes, Robert. “Metafiction.” Iowa Review 1.4 (1970): 100-15.

Siegle, Robert. "Coover's 'The Magic Poker' and the Techniques of Fiction." Essays in Literature 8 (1981): 203-17.

Stengel, Wayne B. "Robert Coover's 'Writing Degree Zero': 'The Magic Poker." Arizona Quarterly 45.2 (1989): 101-10.

Weinstock, E. W. “Robert Coover-'The Babysitter': An Observation on Experimental Writing.” Style 9 (1975): 378-87.

Wilczynski, Marek. “The Game of Response in Robert Coover's Fictions." Kwartalnik Neofilologizny 33 (1986): 513-23. 